\title{
The long-term survival in primary retroperitoneal mucinous cystadenocarcinoma: a case report
}

\author{
Hirotaka Tokai ${ }^{1 *} \mathbb{D}$, Yasuhiro Nagata ${ }^{3}$, Ken Taniguchi $^{1}$, Naomi Matsumura', Amane Kitasato ${ }^{1}$, Takayuki Tokunaga', \\ Hiroaki Takeshita', Tamotsu Kuroki', Shigeto Maeda', Masahiro Ito ${ }^{2}$ and Hikaru Fujioka'
}

\begin{abstract}
Background: Primary retroperitoneal mucinous cystadenocarcinoma (PRMC) is extremely rare, and its biological behavior, pathogenesis, optimum treatments, and prognosis remain to be elucidated. We herein report a case of PRMC with an 80-month follow-up.

Case presentation: A 29-year-old woman was diagnosed with unknown retroperitoneal tumor with benign right ovarian cyst and uterine fibroids, and she underwent laparotomy. The tumor was completely resected with a subsequent histopathological diagnosis of primary retroperitoneal mucinous cystadenocarcinoma (PRMC). Eighty months after surgery, she remains recurrence-free.

Conclusion: PRMC is an extremely rare tumor. Only around 60 cases have so far been published in the literature. The preoperative diagnosis of PRMC is difficult, and a definitive diagnosis can usually only be made based on the findings of histopathological examinations after surgery. Presently, only radical resection is useful for both diagnostic and therapeutic purposes. The optimal long-term management after surgery is still not well established. Further studies on PRMC are therefore needed to elucidate the etiology and establish effective treatments.
\end{abstract}

Keywords: Retroperitoneal, Cystadenocarcinoma, Mucinous

\section{Background}

Primary retroperitoneal mucinous cystadenocarcinoma (PRMC) is extremely rare, with the first case was reported in 1965 [1]. Since then, only 61 cases have been reported in the English literature, to our knowledge. Little is known about the biological behavior and pathogenesis of this disease. The diagnosis is often confusing preoperatively. In addition, the optimum treatments and prognosis of PRMCs remain to be uncertain. We herein report a case of PRMC with 80 months of follow-up.

\section{Case presentation}

A 29-year-old woman was admitted to our hospital for further examination due to abdominal pain and a cystic mass in the right lower abdomen. A physical examination

\footnotetext{
* Correspondence: h-tokai@cj8.so-net.ne.jp

${ }^{1}$ Department of Surgery, National Hospital Organization Nagasaki Medical

Center, Kubara 2-1001-1, Omura, Nagasaki 856-8562, Japan

Full list of author information is available at the end of the article
}

revealed no tumor in her abdomen on palpation. Contrast-enhanced computed tomography (CT) revealed a cystic and well-defined tumor of $8.5 \mathrm{~cm}$ in diameter behind the ascending colon. The tumor had enhanced and segmented components (Fig. 1). Magnetic resonance imaging (MRI) demonstrated a mass behind the ascending colon of iso-intensity on T1-weighted and high intensity on T2-weighted images. Other bi-cystic masses of $8 \mathrm{~cm}$ in diameter at the right ovary and uterine fibroids were also observed (Fig. 2). There was no evidence of invasion to adjacent tissues or distant metastasis. Based on imaging findings, the differential diagnosis of this tumor was thought to be neurogenic tumor, leiomyosarcoma, malignant fibrous histiocytoma, and primary retroperitoneal tumor. The serum levels of carcinoembryonic antigen (CEA) were within normal limits, while those of cancer antigen (CA) 19-9 and 125 (CA125) were elevated. She was diagnosed with unknown retroperitoneal tumor with benign right ovarian cyst and uterine fibroids. 

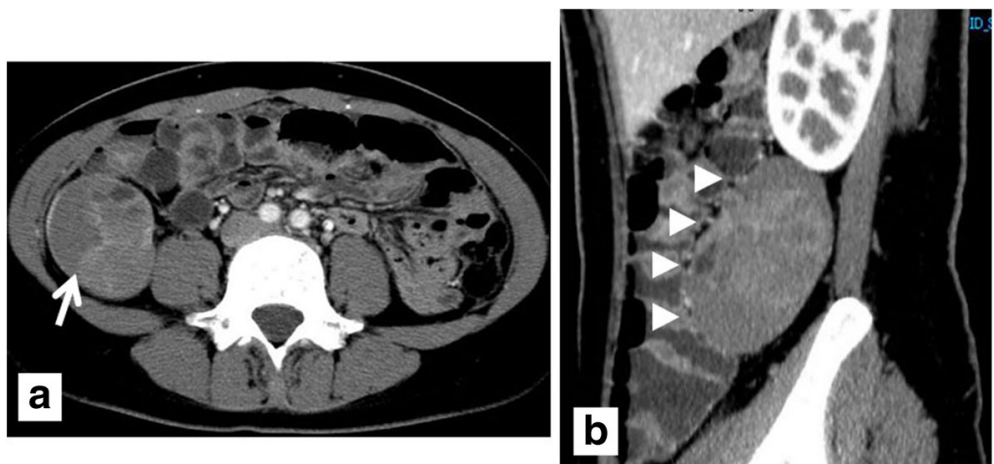

Fig. 1 (a) Horizontal and (b) sagittal image of CT reveals a cystic and well-defined tumor $8.5 \mathrm{~cm}$ in diameter behind the ascending colon (arrow heads) with enhanced and segmented components (arrow)

Laparotomy was performed, revealing a tumor capsulated with a thin wall behind the ascending colon, an ovarian cyst, and uterine fibroids. The tumor was completely removed without injury of its capsule. The ovarian cyst was enucleated, but the uterine fibroids were not removed in accordance with the preoperative informed consent.

A histopathological examination showed that the tumor was unilocular with a large mural solid nodule. In the nodule, there were multi-cystic lesions covered with papillovillous hyperchromatic cells made of intestinal type epithelium ranging from adenoma- to invasive adenocarcinoma type. In addition, ovarianlike stroma was seen in the cyst wall, but ovarian tissue and teratomatous elements were not (Fig. 3).

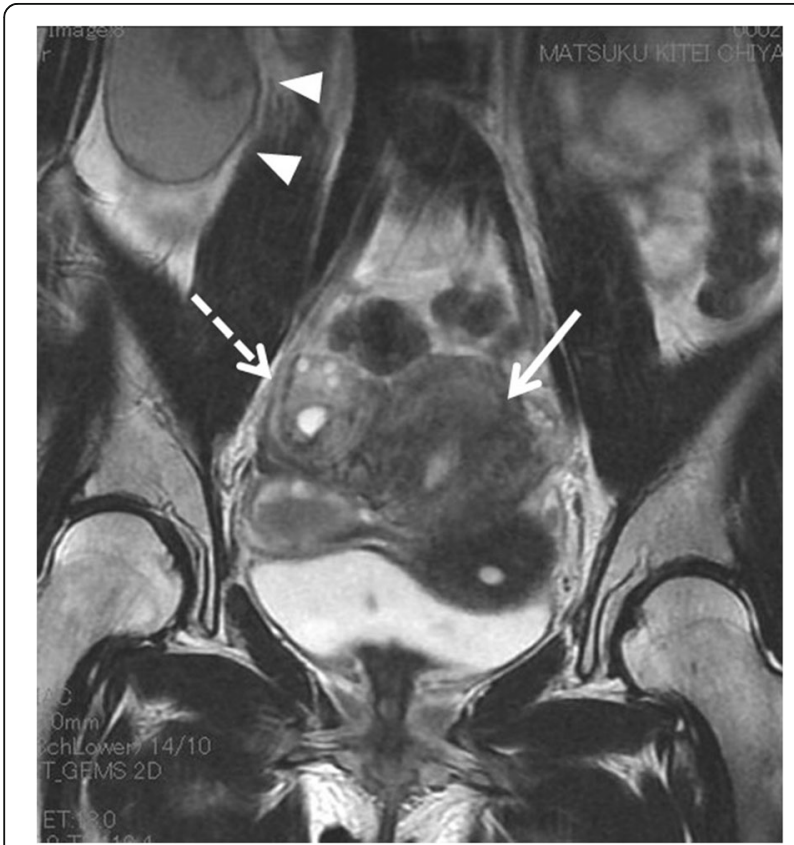

Fig. 2 MRI demonstrates a cystic mass of iso-intensity on T1-weighted and high intensity on T2-weighted images (arrow heads), uterine fibroids (arrow), and cystic masses at the right ovary (broken arrow)
An immuno-histopathological examination revealed positivity for CK 7 and CEA but negativity for CK 20 in the tumor cells (Fig. 4), and negativity for estrogen and progesterone receptors in the ovarian-like stromal cells. Considering the histopathological features and the location, the tumor was diagnosed as PRMC without sarcomatous change.

The surgical margin was free from tumor cells. The right ovarian cyst was diagnosed as an endometrial cyst (chocolate cyst). After the surgery, she had no major complications and left our hospital 8 days later. During the follow-up period of 80 months, neither local recurrence nor distant metastasis was found. Her other ovarian cysts, however, gradually enlarged, so she underwent surgery to remove them 4 years after the initial surgery. A histopathological examination revealed that they were benign chocolate cysts. The serum levels of CA 125 and CA 19-9, which had been elevated before the second surgery, normalized after surgery.

\section{Discussion}

Retroperitoneal mucinous cystic neoplasms, including cystadenoma and cystadenocarcinoma, are so rare that the accurate incidence is not available. We searched the PubMed database for published English studies using the terms "primary" and "retroperitoneal" and "mucinous" and "cystadenocarcinoma" or "adenocarcinoma." Cases of adenomas, borderline tumors, and metastasis to the retroperitoneum were excluded, but mixed-type tumors were included. Our present case is only the 62 nd case (Table 1) [1-46]. The mean age is 44.7 years (range $18-86$ years), and the mean tumor size is $13.6 \mathrm{~cm}$ (range 3 to $26 \mathrm{~cm}$ ). Only five cases were reported in males. To our knowledge, among the 51 cases in which the followup period was mentioned (range 1-130 months; median 16 months), only 7 cases had been followed for over 5 years. They are all alive without recurrence of disease. Although most PRMCs tend not to develop further disease, some with sarcoma-like or anaplastic components 


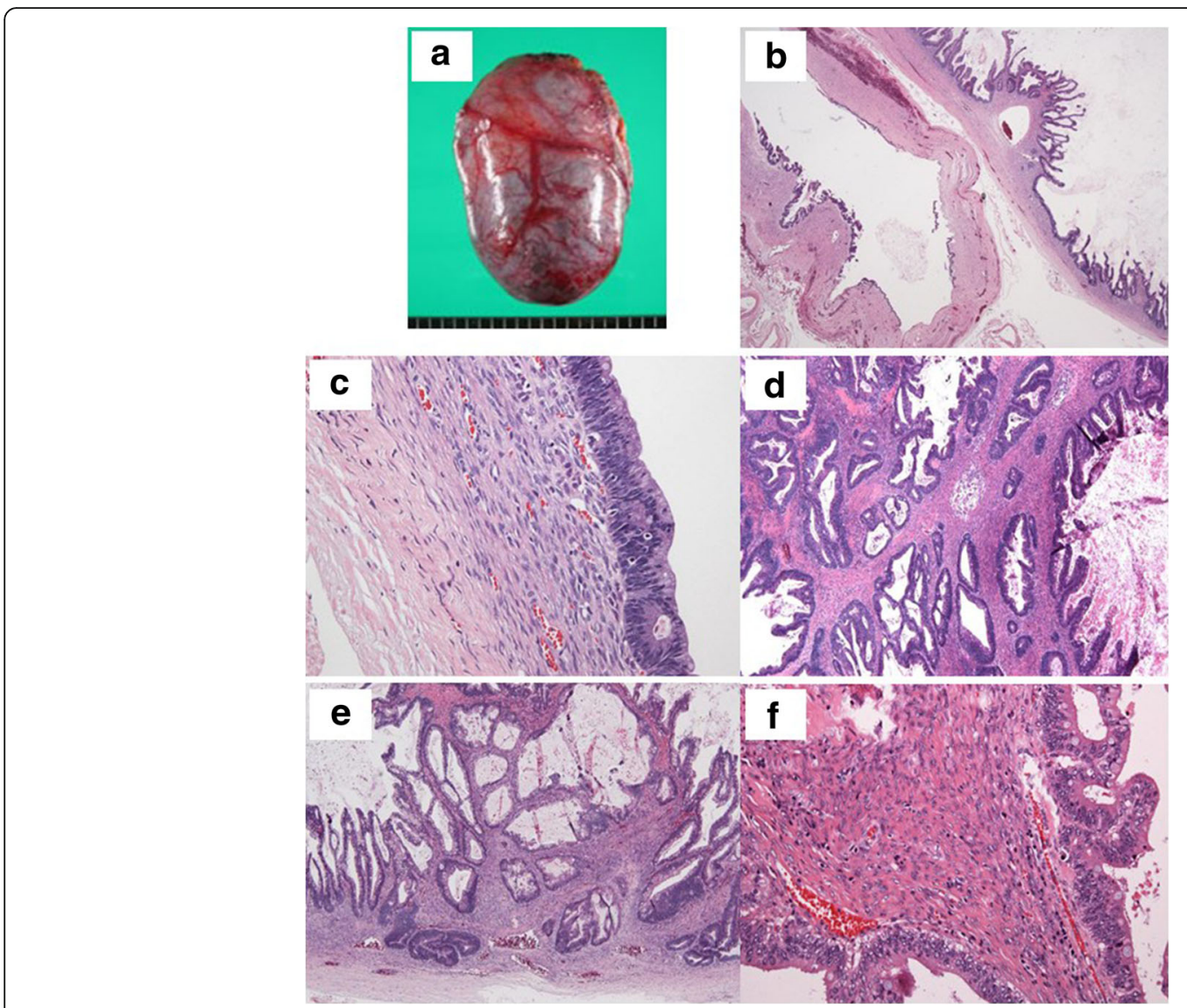

Fig. 3 Gross appearance of the specimen (a). Microscopic images show that the tumor consists of a unilocular cyst and a large mural solid nodule (b). In the nodule, multi-cystic lesions covered by papillovillous hyperchromatic cells are observed. They comprise intestinal-type epithelium with goblet cells $(\mathbf{c})$. Some of them are invasive adenocarcinoma cells (d) with stromal invasion (e). Ovarian-like stroma is also observed (f)

have a very aggressive character and can metastasize. Myriokefalitaki [9] reported that the 5-year overall survival was $75.4 \%$.

The etiology and biological behavior of PRMCs are still unclear; however, some hypotheses have been proposed to explain the genesis of these tumors as follows: (1) heterotopic ovarian tissue [3, 11, 47], (2) monodermal variant of teratomas [22, 48], (3) intestinal duplication [49], and (4) coelomic metaplasia [4, 8, 12, 50]. In our case, ovarian-like stroma was histopathologically found in the tumor, although no definitive evidence of ovarian tissue was observed, which was also supported by the results of an immunohistochemical examination of the estrogen and progesterone receptors. These findings exclude the hypothesis of heterotopic ovarian tissue. In addition, the hypotheses of teratoma and intestinal duplication can also be excluded because of the lack of structures of teratoma or well-developed intestinal mucosa and smooth muscle. The fourth hypothesis, which is most well-described in the previous literature,

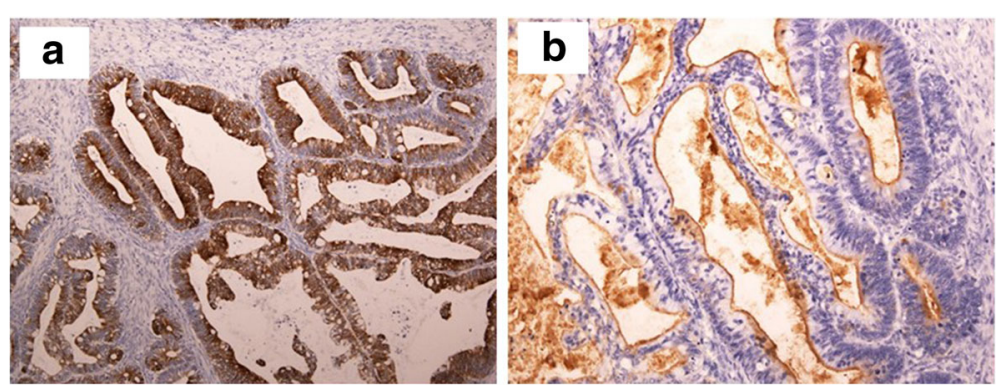

Fig. 4 An immuno-histopathological examination revealed positivity for CK 7 (a) and CEA (b) but negativity for CK 20 in the tumor cells 
Table 1 Published English studies searched in PubMed

\begin{tabular}{|c|c|c|c|c|c|c|c|}
\hline Case no. & Author & Sex & Age & Diameter(cm) & $\begin{array}{l}\text { Adjuvant } \\
\text { chemotherapy }\end{array}$ & $\begin{array}{l}\text { Follow-up } \\
\text { (month) }\end{array}$ & Status \\
\hline 1 & Douglas 1965 [1] & $\mathrm{F}$ & 18 & 5 & No & $N / R$ & DOD \\
\hline 2 & Tykkä 1975 [2] & $\mathrm{F}$ & 23 & 10 & No & 11 & DOD \\
\hline 3 & Roth 1977 [3] & $\mathrm{F}$ & 48 & $N / R$ & No & 6 & DOD \\
\hline 4 & Fujii 1986 [4] & $\mathrm{F}$ & 69 & 23 & No & 36 & NED \\
\hline 5 & Nelson 1988 [5] & $\mathrm{F}$ & 35 & 20 & No & 22 & NED \\
\hline 6 & Chida 1990 [6] & $\mathrm{F}$ & 42 & $N / R$ & No & $N / R$ & $N / R$ \\
\hline 7 & Seki 1990 [7] & $\mathrm{F}$ & 42 & 11 & No & $N / R$ & $N / R$ \\
\hline 8 & Park 1990 [8] & $\mathrm{F}$ & 40 & 24 & Yes & 3 & NED \\
\hline 9 & Jorgensen 1991 [9] & $\mathrm{F}$ & 38 & 8 & No & 9 & NED \\
\hline 10 & Søndergaard 1991 [10] & $\mathrm{F}$ & 37 & 13 & No & 18 & NED \\
\hline 11 & Gotoh 1992 [11] & $\mathrm{F}$ & 44 & 12.5 & Yes & 4 & DOD \\
\hline 12 & Tenti 1994 [12] & $\mathrm{F}$ & 46 & 20 & Yes & 33 & NED \\
\hline 13 & & $\mathrm{~F}$ & 45 & 20 & No & 19 & NED \\
\hline 14 & Motoyama 1994 [13] & $\mathrm{F}$ & 42 & 11 & $N / R$ & $N / R$ & $N / R$ \\
\hline 15 & Carabias 1995 [14] & $\mathrm{F}$ & 43 & 15 & No & 24 & NED \\
\hline 16 & Lee 1996 [15] & $\mathrm{F}$ & 55 & 20 & No & 30 & NED \\
\hline 17 & & $\mathrm{~F}$ & 45 & 17 & No & 15 & NED \\
\hline 18 & Dore 1996 [16] & $\mathrm{F}$ & 45 & 20 & No & 16 & NED \\
\hline 19 & Uematsu 2000 [17] & $\mathrm{F}$ & 86 & 23 & No & 72 & NED \\
\hline 20 & Suzuki 2001 [18] & $\mathrm{F}$ & 40 & 15 & No & 15 & NED \\
\hline 21 & Tangjitgamol 2002 [19] & $\mathrm{F}$ & 41 & 12 & Yes & 18 & NED \\
\hline 22 & Kessler 2002 [20] & $\mathrm{F}$ & 38 & 11.5 & $N / R$ & 60 & NED \\
\hline 23 & Mikami 2003 [21] & $\mathrm{F}$ & 38 & 16 & Yes & 18 & DOD \\
\hline 24 & Song 2005 [22] & $\mathrm{F}$ & 72 & 12 & No & 4 & DOD \\
\hline 25 & Sonntag 2005 [23] & $\mathrm{F}$ & 60 & 5 & No & 12 & NED \\
\hline 26 & Thamboo 2006 [24] & M & 64 & 24 & No & 18 & NED \\
\hline 27 & Fan 2006 [25] & $\mathrm{F}$ & 68 & 17 & No & $N / R$ & $\mathrm{~N} / \mathrm{R}$ \\
\hline 28 & Law 2006 [26] & $\mathrm{F}$ & 35 & 11 & No & 60 & NED \\
\hline 29 & de Leon 2007 [27] & $\mathrm{F}$ & 36 & 19 & Yes & 8 & AWD \\
\hline 30 & & $\mathrm{~F}$ & 21 & 26 & No & 6 & NED \\
\hline 31 & Kashima 2007 [28] & $\mathrm{F}$ & 28 & 17 & No & 13 & NED \\
\hline 32 & Lee 2007 [29] & $\mathrm{F}$ & 32 & 15 & Yes & 42 & NED \\
\hline 33 & Green 2007 [30] & M & 83 & 26 & No & 6 & NED \\
\hline 34 & Tjalma 2007 [31] & $\mathrm{F}$ & 74 & 3 & Yes & 31 & DOD \\
\hline 35 & Moral 2008 [32] & $\mathrm{F}$ & 47 & 24 & No & 8 & NED \\
\hline 36 & Youssef 2008 [33] & $\mathrm{F}$ & 70 & 10 & Yes & 24 & NED \\
\hline 37 & Roma 2009 [34] & $\mathrm{F}$ & 35 & 13 & No & 13 & NED \\
\hline 38 & & $\mathrm{~F}$ & 47 & 21 & No & 1 & NED \\
\hline 39 & & $\mathrm{~F}$ & 24 & 18 & No & 2 & NED \\
\hline 40 & & $\mathrm{~F}$ & 43 & 10 & No & 5 & DOD \\
\hline 41 & & $F$ & 40 & 11 & No & 9 & DOD \\
\hline 42 & & $\mathrm{~F}$ & 27 & 8 & No & 11 & NED \\
\hline 43 & & $\mathrm{~F}$ & 63 & 7.5 & No & 14 & AWD \\
\hline
\end{tabular}


Table 1 Published English studies searched in PubMed (Continued)

\begin{tabular}{|c|c|c|c|c|c|c|c|}
\hline Case no. & Author & Sex & Age & Diameter(cm) & $\begin{array}{l}\text { Adjuvant } \\
\text { chemotherapy }\end{array}$ & $\begin{array}{l}\text { Follow-up } \\
\text { (month) }\end{array}$ & Status \\
\hline 44 & & $\mathrm{~F}$ & 31 & 18 & No & 26 & AWD \\
\hline 45 & & $\mathrm{~F}$ & 48 & 26 & No & 58 & AWD \\
\hline 46 & & $\mathrm{~F}$ & 40 & 15 & No & 58 & NED \\
\hline 47 & & $\mathrm{~F}$ & 35 & $N / R$ & No & 91 & NED \\
\hline 48 & & $\mathrm{~F}$ & 49 & 11 & No & 130 & NED \\
\hline 49 & & $\mathrm{~F}$ & 20 & $N / R$ & No & $N / R$ & $N / R$ \\
\hline 50 & Hrora 2009 [35] & M & 42 & 5 & No & 6 & NED \\
\hline 51 & Dierickx 2010 [36] & $\mathrm{F}$ & 50 & 13 & Yes & 58 & NED \\
\hline 52 & Jian 2011 [37] & $\mathrm{F}$ & 21 & 14.6 & Yes & 6 & AWD \\
\hline 53 & Kanayama 2012 [38] & $\mathrm{F}$ & 40 & 25 & No & 6 & AWD \\
\hline 54 & Feng 2013 [39] & M & 63 & 4 & No & 13 & NED \\
\hline 55 & Hanhan 2014 [40] & $\mathrm{F}$ & 37 & 22 & No & $\mathrm{N} / \mathrm{R}$ & $N / R$ \\
\hline 56 & Shiau 2013 [41] & M & 59 & 7.5 & No & 79 & NED \\
\hline 57 & Kurita 2014 [42] & $\mathrm{F}$ & 30 & 19 & No & 32 & AWD \\
\hline 58 & Kamiyama 2015 [43] & $\mathrm{F}$ & 62 & 10 & No & 15 & DOD \\
\hline 59 & Cupp 2015 [44] & $\mathrm{F}$ & 39 & 20 & Yes & $N / R$ & $N / R$ \\
\hline 60 & Dong 2014 [45] & $\mathrm{F}$ & 52 & 3.8 & No & $N / R$ & $N / R$ \\
\hline 61 & Myriokefalitaki 2016 [46] & $\mathrm{F}$ & 56 & 24 & No & 17 & NED \\
\hline 62 & Present case & $\mathrm{F}$ & 28 & 8.5 & No & 80 & NED \\
\hline
\end{tabular}

$N / R$ not recorded, $D O D$ dead of disease, NED no evidence of disease, $A W D$ alive with disease

is that PMRCs occur from invaginations of the peritoneal epithelium during embryogenesis. Those invaginated coelomic epithelial cells form cysts that may act like epithelial ovarian tissue and undergo the process of Müllerian differentiation. Eventually, the coelomic epithelia of these cysts undergo metaplasia and develop a spectrum of histological cells in different stages. In our case, the ovarianlike stroma and intestinal type epithelium ranged from adenoma-type mucinous cells to invasive adenocarcinoma cells, which may be explained by the last theory. In addition, the pattern of immunohistochemical expression of CK 7 and CK 20 is similar to those seen in ovarian and pancreatic mucinous neoplasms.

There are no pathognomonic clinical or radiological findings for PRMC, making the preoperative diagnosis of this disease challenging. PRMCs usually present as a multi- or unilocular cystic mass, varying in size and localized anywhere in the retroperitoneal space. Regarding the imaging findings, the diagnostic value of computed tomography and MRI is similar, but MRI can further characterize these lesions and identify their mucinous component. Notable radiographic findings may include thickening and calcification of the cyst wall or mural nodules on imaging that may suggest malignant lesions [27]. Aspiration cytology and/or a biopsy may help with the diagnosis, although they carry risks of recurrence and dissemination in cystic tumors. Serological investigations provide limited diagnostic utility.
Tumor markers, including CEA, CA 125, and CA 19-9, are also not very helpful for differentiating from other benign tumors, including ovarian cyst, cystic lymphangioma, and cystic methothelioma. Indeed, in our case, the elevation of serum levels of CA19-9 and CA 125 was also observed during the follow-up period. However, these levels normalized after she underwent a second surgery to resect the benign ovarian cysts. Therefore, imaging examinations such as CT or ultrasonography are the most effective tools for performing follow-up for PRMC.

The management of PRMC is not well established. There is currently no significant chemotherapy for PRMC. The commonly used chemotherapeutic regimes were cyclophosmide and adriamycin, cyclophosmide, adriamycin and cisplatin, cisplatin alone, carboplatin and paclitaxel, or carboplatin alone. Of the 12 patients who received adjuvant chemotherapy, 5 had recurrence $(41.7 \%)$. Therefore, radical tumor excision is clearly mandatory. Radical resection without rupture is the standard therapy and the most important prognostic tool [46], but whether lymphadenectomy or adjuvant chemotherapy provide benefit is still controversial $[11,12,19,21,27,29,31,36]$.

\section{Conclusions}

PRMC is a rare tumor that can have an aggressive potential for recurrence. The diagnosis remains difficult preoperatively, and surgeons should be aware of this disease as a differential 
diagnosis of large retroperitoneal cystic masses with indolent symptoms. The long-term management after surgery is not well established yet. Further studies about PRMC are needed to elucidate the etiology and effective treatments.

\author{
Abbreviations \\ CA: Cancer antigen; CEA: Carcinoembryonic antigen; CT: Computed \\ tomography; MRI: Magnetic resonance imaging; PRMC: Primary \\ retroperitoneal mucinous cystadenocarcinoma
}

\section{Funding}

The authors declare no financial or any other type of support.

\section{Authors' contributions}

$\mathrm{HT}$ drafted the manuscript. YN participated in the surgery and supervised the writing of the manuscript. KT, NM, AK, TT, HT, TK, and SM performed perioperative management on the patient and helped to draft the manuscript. HF is a chairperson of our department who supervised the entire process. Ml helped to draft the manuscript of the pathological findings. All authors read and approved the final manuscript.

\section{Ethics approval and consent to participate}

This article does not contain any studies involving human participants, human data, or human tissue, so our manuscript is not applicable in this section.

\section{Consent for publication}

The patient has provided permission to publish these features of the cases, and the identity of the patient has been protected.

\section{Competing interests}

The authors declare that they have no competing interests.

\section{Publisher's Note}

Springer Nature remains neutral with regard to jurisdictional claims in published maps and institutional affiliations.

\section{Author details}

${ }^{1}$ Department of Surgery, National Hospital Organization Nagasaki Medical Center, Kubara 2-1001-1, Omura, Nagasaki 856-8562, Japan. ${ }^{2}$ Department of pathology, National Hospital Organization Nagasaki Medical Center, Kubara 2-1001-1, Omura, Nagasaki 856-8562, Japan. ${ }^{3}$ Center for Comprehensive Community Care Education Nagasaki University Graduate School of Biomedical Sciences, Nagasaki, Japan.

Received: 17 August 2017 Accepted: 15 November 2017 Published online: 25 November 2017

\section{References}

1. Douglas GW, Kastin AJ, Huntington RW. Carcinoma arising in a retroperitoneal Müllerian cyst, with widespread metastasis during pregnancy. Am J Obstet Gynecol. 1965;91(2):210-6.

2. Tykkä H, Koivuniemi A. Carcinoma arising in a mesenteric cyst. Am J Surg. 1975;129(6):709-11.

3. Roth LM, Ehrlich CE. Mucinous cystadenocarcinoma of the retroperitoneum. Obstet Gynecol. 1977;49(4):486-8

4. Fuji S, Konishi I, Okamura H, Mori T. Mucinous cystadenocarcinoma of the retroperitoneum: a light and electron microscopic study. Gynecol Oncol. 1986;24(1):103-12.

5. Nelson H, Benjamin B, Alberty R. Primary retroperitoneal mucinous cystadenocarcinoma. Cancer. 1988;61(10):2117-21.

6. Chida T, Watanabe H, Motoyama T, Ajioka Y, Honma T, Kurosaki I, et al. A case of retroperitoneal mucinous cystadenocarcinoma. Gan No Rinsho. 1990;36(2):205-10.

7. Seki H, Shiina M, Nishihara M, Kimura M, Kamura T, Sakai K, et al. Primary retroperitoneal mucinous cystadenocarcinoma: report of a case. Radiat Med. 8(5):164-7.

8. Park U, Han KC, Chang HK, Huh MH. A primary mucinous cystoadenocarcinoma of the retroperitoneum. Gynecol Oncol. 1991;42(1): $64-7$.
9. Jørgensen $L$, Vibits $H$. Primary retroperitoneal mucinous cystadenocarcinoma. A case report and review of the literature. APMIS. 1991;99:1055-7.

10. Søndergaard, G. \& Kaspersen, P. Ovarian and extraovarian mucinous tumors with solid mural nodules. Int J Gynecol Pathol 1991 10, 145-55.

11. Gotoh K, Konaga E, Arata A, Takeuchi H, Mano SA. Case of primary retroperitoneal mucinous cystadenocarcinoma. Acta Med Okayama. 1992;46:49-52.

12. Tenti $P$, Carnevali L, Tateo S, Durola R. Primary mucinous cystoadenocarcinoma of the retroperitoneum: two cases. Gynecol Oncol. 1994:55:308-12.

13. Motoyama T, Chida T, Fujiwara T, Watanabe H. Mucinous cystic tumor of the retroperitoneum. A report of two cases. Acta Cyto. 1994;38:261-6.

14. Carabias E, Garcia Muñoz H, Dihmes FP, López Pino MA, Ballestín C. Primary mucinous cystadenocarcinoma of the retroperitoneum. Report of a case and literature review. Virchows Arch. 1995;426:641-5.

15. Lee IW, Ching KC, Pang M, Ho TH. Two cases of primary retroperitoneal mucinous cystadenocarcinoma. Gynecol Oncol. 1996;63:145-50.

16. Dore $R$, et al. Primitive mucinous cystadenocarcinoma of the retroperitoneum. Case report and diagnostic considerations. Clin Imaging 1996;20:129-32.

17. Uematsu T, et al. Ruptured retroperitoneal mucinous cystadenocarcinoma with synchronous gastric carcinoma and a long postoperative survival: case report. J Surg Oncol. 2000;73:26-30.

18. Suzuki S, Mishina T, Ishizuka D, Fukase M, Matsubara YI. Mucinous cystadenocarcinoma of the retroperitoneum: report of a case. Surg Today. 2001;31:747-50

19. Tangjitgamol S, et al. Retroperitoneal mucinous cystadenocarcinoma: a case report and review of literature. Int J Gynecol. Cancer 2002;12:403-8.

20. Kessler TM, Kessler W, Neuweiler J, Nachbur BH. Treatment of a case of primary retroperitoneal mucinous cystadenocarcinoma: is adjuvant hysterectomy and bilateral salpingo-oophorectomy justified? Am J Obstet Gynecol. 2002;187:227-32.

21. Mikami M, et al. Retroperitoneal primary mucinous adenocarcinoma with a mural nodule of anaplastic tumor: a case report and literature review. Int J Gynecol Pathol. 2003;22:205-8.

22. Song E-S, et al. Mucinous adenocarcinoma arising from one retroperitoneal mature cystic teratoma in a postmenopausal woman. J Obstet Gynaecol Res. 2005:31:127-32.

23. Sonntag B, et al. Retroperitoneal mucinous adenocarcinoma occuring during pregnancy in a supernumerary ovary. J Obstet Gynaecol (Lahore). 2005;25:515-6.

24. Thamboo TP, Sim R, Tan S-Y, Yap W-M. Primary retroperitoneal mucinous cystadenocarcinoma in a male patient. J Clin Pathol. 2006;59:655-7.

25. Fan YS, Thomas TMM, Ip PPC, Cheung ANY. Osteoid-forming sarcoma-like mural nodule in a retroperitoneal mucinous cystadenocarcinoma. Histopathology. 2006;49:201-4.

26. Law KS, Chang TM, Tung JN. Fertility-sparing treatment of a primary retroperitoneal mucinous cystadenocarcinoma. BJOG. 2006;113:612-4.

27. de León DC, et al. Primary retroperitoneal mucinous cystadenocarcinoma: report of two cases. World J Surg Oncol. 2007;5:5.

28. Kashima K, Yahata T, Fujita K. Tanaka K. Primary retroperitoneal mucinous cystadenocarcinoma associated with pregnancy. Int J Gynecol Cancer. 2008; 18:908-12.

29. Lee SA, et al. Primary retroperitoneal mucinous cystadenocarcinoma: a case report and review of the literature. Korean J Intern Med. 2007;22:287-91.

30. Green JM, Bruner BC, Tang WW, Orihuela E. Retroperitoneal mucinous cystadenocarcinoma in a man: case report and review of the literature. Urol Oncol. 2007;25:53-5.

31. Tjalma WAA, Vaneerdeweg W. Primary retroperitoneal mucinous cystadenocarcinomas are a distinct entity. Int J Gynecol Cancer. 2007;18:184-8

32. Moral González M, García-Blanch de Benito G, Sánchez Gil A, Díaz García GA, Cuberes Monserrat R. Primary retroperitoneal mucinous cystadenocarcinoma. Cir Esp. 2008;84:169-71.

33. Youssef $C$, et al. Primary retroperitoneal endometrial cystadenocarcinoma presenting as pelvic abscess on ultrasound. Ultrasound Obstet Gynecol. 2008;31:714-5.

34. Roma AA, Malpica A. Primary retroperitoneal mucinous tumors: a clinicopathologic study of 18 cases. Am J Surg Pathol. 2009;33:526-33.

35. Hrora $A$, et al. Primary retroperitoneal mucinous cystadenocarcinoma in a male patient: a case report. Cases J. 2009;2:7196. 
36. Dierickx I, et al. Primary retroperitoneal mucinous cystadenocarcinoma: a case report and review of the literature. Gynecol Obstet Investig. 2010;70:186-91.

37. Jiang $H$, Jin $K$, You Q, Fang W, Xu N. Retroperitoneal primary mucinous adenocarcinoma: a case report. Oncol Lett. 2011;2:633-6.

38. Kanayama $T$, et al. Primary retroperitoneal mucinous cystadenocarcinoma with mural nodules: a case report and literature review. Int J Clin Oncol. 2012;17:407-11.

39. Feng J, Liu H, Chen D. Primary retroperitoneal mucinous cystadenocarcinoma in a male patient: a rare case report. Hippokratia. 2013;17:271-3.

40. Hanhan HM, et al. Primary retroperitoneal mucinous cystadenocarcinoma during pregnancy. J Obstet Gynaecol. 2014;34:535-8.

41. Shiau J-P, Wu C-T, Chin C-C, Chuang C-K. Long-term survival after handassisted laparoscopic approach of primary retroperitoneal mucinous cystadenocarcinoma in male: case report and review of literature. Eur Surg. 2013;45:106-9.

42. Kurita T, Nakajima K, Koi C, Matsuura Y, Hachisuga T. Management of a primary retroperitoneal mucinous cystadenocarcinoma: case report. Eur J Gynaecol Oncol. 2014;35:163-6.

43. Kamiyama $\mathrm{H}$, et al. Report of a case: retroperitoneal mucinous cystadenocarcinoma with rapid progression. Int J Surg Case Rep. 2015;10:228-31.

44. Cupp JS, Illeck J, Rahbar N, Rettenmaier MA, Goldstein BH. A rare case of primary retroperitoneal mucinous adenocarcinoma: a case report J Reprod Med. 2015;58:85-8.

45. Dong B, Zhou H, Zhang J, Wang Y, Fu Y. Diagnosis and treatment of retroperitoneal bronchogenic cysts: a case report. Oncol Lett. 2014;7:2157-9.

46. Myriokefalitaki E, Luqman I, Potdar N, Brown L, Steward W, Moss EL. Primary retroperitoneal mucinous cystadenocarcinoma (PRMCa): a systematic review of the literature and meta-analysis. Arch Gynecol Obstet. 2016;293(4):709-20.

47. Storch MP, Raghavan U. Mucinous cystadenocarcinoma of retroperitoneum. Conn Med. 1980:44(3):140-1.

48. Pennell TC, Gusdon JP. Retroperitoneal mucinous cystadenoma. Am J Obstet Gynecol. 1989;160(5 Pt 1):1229-31.

49. Abascal J, Ardaiz J, Gil P, Menéndez J, Barreiro JJ, Inchausti JL. [Primary retroperitoneal cyst (possible intestinal origin)]. Rev Esp Enferm Apar Dig. 1977 51(7):819-828.

50. Pearl ML, Valea F, Chumas J, Chalas E. Primary retroperitoneal mucinous cystadenocarcinoma of low malignant potential: a case report and literature review. Gynecol Oncol. 1996:61(1):150-2.

\section{Submit your manuscript to a SpringerOpen ${ }^{\circ}$ journal and benefit from:}

- Convenient online submission

- Rigorous peer review

- Open access: articles freely available online

- High visibility within the field

- Retaining the copyright to your article

Submit your next manuscript at $\gg$ springeropen.com 